\title{
Un estudio sobre las Cartas de Catón (1720-1723) y su difusión en las colonias británicas de Norteamérica
}

\section{A Study on Cato's Letters (1720-1723) and its Dissemination in the British Colonies of North America}

\author{
Ricardo Cueva FERNÁNDEZ \\ Universidad Carlos III \\ ricardo.cueva@uc3m.es
}

Recibido: $11 / 12 / 2012$

Aceptado: 20/02/2014

\section{Resumen}

Cierta tendencia "revisionista" aparecida a finales de los 60' vino a indicar que la historiografía tradicional habría soslayado los rasgos republicanos de la emancipación estadounidense y exagerado por contra la influencia de John Locke. Uno de los textos en que aquella corriente crítica se apoyó fueron las Cartas de Catón (172023). Sin embargo, su lectura atenta conduce a entenderlas como mucho más próximas al citado pensador, sobre todo si consideramos su concepto de propiedad y su teoría contractualista. Es más, sus autores asumieron la emergencia de la sociedad comercial e hicieron hincapié en las libertades religiosa y de expresión y en los derechos de participación política en un grado mucho mayor que John Locke. Trenchard y Gordon estuvieron preocupados porque la concentración de poder político condujera a vulnerar los derechos de los súbditos ingleses y abogaron en consecuencia por un estricto control de los gobernantes. Sin embargo, no llegaron a desembocar en una reflexión de carácer democrático, debido a que, aunque atribuían capacidad epistémica al individuo, bajo el principio de la libre disposición de sí mismo, no se la reconocían al pueblo como colectivo.

Palabras clave: Cartas de Catón, derechos, republicanismo, Estados Unidos, democracia.

\begin{abstract}
Some "revisionist" trends in the late 1960s on the history of American emancipation suggested that existing historiography had, on the one hand, underestimated its republican features and, on the other, exaggerated John Locke's influence. These re-
\end{abstract}


vionists attached great importance to Cato's Letters (1720-23), written by John Trenchard and Thomas Gordon, as an example of republican influence. However, close scrutiny of the Letters shows that that this text was, in fact, close to the thought of Locke, above all his concept of property and contractualist theory. Despite these important similarities, though, there were also key differences: to a much greater extent than Locke, its authors assumed the emergence of commercial society and emphasized freedom of religion and speech and rights of political participation. Since Trenchard and Gordon feared that the concentration of political power violated the rights of British, they advocated the strict control of the executive and the frequent Parliament elections. However, their proposed system was far from being democratic and inclusive. Trenchard and Gordon did not advance a democratic approach because, although they attached epistemic capacity to the individual under the principle of self-ownership, they did not acknowledge the same for the people as collective.

Keywords: Cato's Letters, rights, republicanism, United States, democracy.

\section{Introducción*}

A lo largo de las últimas décadas se edificado una destacable historiografía acerca de la ideología en el mundo atlántico y entre sus numerosas reflexiones han cobrado especial relevancia las referentes a la independencia y al nacimiento de los Estados Unidos. Las líneas de investigación acerca del peculiar fenómeno político que supusieron las colonias inglesas en Norteamérica durante los siglos XVII y XVIII han sido numerosas, pero la más prestigiosa tras la segunda Guerra Mundial fue la de Louis Hartz con su The Liberal Tradition in America (1955), en donde este historiador identificaría la impronta lockeana con el ethos del país ${ }^{1}$, pero encontró una crítica poderosa en The Ideological Origins of the American Revolution (1967) de Bernard Bailyn². Bailyn analizó la literatura colonial escrita entre 1760 y 1776, con-

\footnotetext{
* Agradezco sus observaciones a los evaluadores de la versión preliminar del presente texto.

${ }^{1}$ Heredando así a C. L. Becker y The Declaration of Independence: A Study on the History of Political Ideas, New York, Harcourt, Brace and Co., 1922.

${ }^{2}$ B. Bailyn, The Ideological Origins of the American Revolution, Cambridge, Harvard University Press, 1967; trad. cast., por donde se cita, de Alberto Vanasco y Antonio Lastra, Los origenes ideológicos de la Revolución norteamericana (con Estudio preliminar de Víctor Méndez Baiges), Madrid, Tecnos, 2012. Bailyn a su vez había seguido algunos hallazgos de C. Robbins y The Eighteenth-century Commonwealthman (Studies in the Transmission, Development, and Circumstance of English Liberal Thought from the Restoration of Charles II until the War with the Thirteen Colonies); utilizo la reed. de Indianapolis, Liberty Fund, 2004. Robbins ya había apuntado en esta dirección antes con su artículo “Algernon Sidney's Discourses Concerning Government: Textbook of Revolution", William and Mary Quarterly, vol. 4, n 3, pp. 267-296
} 
cluyendo que, junto con la la Ilustración ${ }^{3}$, el common law y el puritanismo del covenant ${ }^{5}$, había existido una corriente olvidada y mayor importancia que la de Locke. Esta "influencia" habría ensamblado tales "disímiles corrientes de pensamiento"6, predominando "en el misceláneo conocimiento de los colonos" y transformándolo "en un conjunto coherente", siendo suministrada además por un grupo de autores cuyos orígenes se encontraban "en el pensamiento social y político de tendencia radical elaborado en Inglaterra durante la Guerra Civil en el período de la Commonwealth" . Bailyn señalaba así que "las convicciones efectivas y detonantes" que yacían tras la Revolución no derivaban "de las comunes generalidades lockeanas", ni de su teoría sobre los derechos naturales, sino de los miedos específicos y las formulaciones de publicistas radicales y políticos de la oposición de la Inglaterra de comienzos del siglo XVIII ${ }^{8}$. Con estas reflexiones, Bailyn defendía que las ideas de "esclavitud", "corrupción", o "conspiración"9 habían sido asumidas con toda seriedad por los colonos emancipados ${ }^{10}$, quienes pensaban, igual que los autores británicos de la "oposición" al gobierno", que existía un complot desde idéntico centro de poder para aniquilar sus libertades ${ }^{12}$ mediante el otorgamiento de pensiones y cargos a aquellos miembros del Parlamento que apoyaran al gobierno de la Corona y sus tributos, la constitución de un ejército permanente y la extensión de la deuda nacional ${ }^{13}$. Como uno de los principales ejemplos de esta corriente, Bailyn vino a subrayar la importancia de las Cartas de Catón, escritas por los publicistas londinenses John Trenchard y Thomas Gordon entre 1720 y 1723.

La senda historiográfica de Bailyn sería continuada por Gordon S. Wood con su The Creation of the American Republic, 1776-1787 (1969) ${ }^{14}$, quien señaló que la ideología de los revolucionarios norteamericanos había puesto por encima del bien particular el bien común, favoreciendo la interpretación política del Country frente a

\footnotetext{
${ }^{3}$ Los orígenes ideológicos..., op. cit., pp. 39-42.

${ }^{4}$ Ibidem, pp. 42 y 43.

${ }^{5}$ Ibidem, p. 44.

${ }^{6}$ Con "evidentes incongruencias y contradicciones"; ibidem, p. 45.

${ }^{7}$ Ibidem, p. 46.

${ }^{8}$ B. Bailyn, The Origins of American Politics (Charles K. Colver Lectures, 1965), New York, Random House, 1970; pp. ix y x. Los subrayados son propios.

${ }^{9}$ Los orígenes ideológicos..., op. cit., p. 6.

${ }^{10}$ Ibidem, p. 7.

${ }^{11}$ Ibidem, pp. 46, 50 y 55. "Ellos contribuyeron a formar el pensamiento de la generación revolucionaria noreteamericana mucho más que cualquier otro grupo aislado de escritores" (ibidem,p. 47).

${ }^{12}$ Ibidem, pp. 127-30.

${ }^{13}$ Ibidem, pp. 59-61.

${ }^{14}$ G. S. Wood, The Creation of the American Republic (1776-1787), $2^{\mathrm{a}}$ ed (1 ${ }^{\mathrm{a}}$, de 1969), Chapel Hill, University of North Carolina Press, 1998.
} 
la Court ${ }^{15}$. En este sentido, el radicalismo de los "real whigs" ${ }^{16}$, es decir, de aquellos situados "a la izquierda de la línea whig oficial" inglesa, había sido el mejor acogido por los colonos, por haber mantenido una "fiera y completa resistencia a aceptar los avances del siglo XVIII" y reaccionado "contra la maduración del imperio, con todo lo que ello implicaba en cuanto a uso del dinero y de la burocracia en la tarea gubernamental"17. El libro de Wood, así, se basa en una ampliación de aspectos apuntados por Bailyn, entendiendo que en la etapa de 1776 a 1787 había predominado un discurso que apelaba a la virtud cívica e indisolublemente unido a la participación en el autogobierno colonial y en la evitación de las maniobras corruptas de gobernadores y delegados de la Corona mediante la disminución de su poder frente al de las asambleas $^{18}$. Wood entiende que los colonos percibían su sociedad de forma "organicista"19 y no duda en denominar como "republicana" aquella ideología que predominaba en América y que implicaba "el sacrificio del interés individual al bien más relevante de todo el conjunto" 20 . Para respaldar su tesis se basaba, al igual que su antecesor, en las publicaciones coloniales de la época, y entre ellas señalaba como muy influyentes, una vez más, las Cartas de Trenchard y Gordon, quienes habrían sido así los principales guardianes y transmisores de "los ideales... del republicanismo clásico"21.

\footnotetext{
${ }^{15}$ Ibidem, p. 14.

${ }^{16}$ Noción extraída de C. Robbins, The Eighteenth-century..., op. cit., p. 3.

${ }^{17}$ G. S. Wood, The Creation..., op. cit., p. 15. Los subrayados son propios.

${ }^{18}$ Ibidem, pp. 156 y 157.

19 "Organic chain" porque "una vez se considerara que el pueblo estaba compuesto de diversos intereses opuestos entre sí, todo el sentido de la cadena gradual orgánica en la jerarquía social se convertía en irrelevante, hecho simbolizado por el énfasis progresivo en la imagen del contrato social". Ibidem, p. 607.

20 "El sacrificio del interés individual al bien más destacado de todo el conjunto conformó la esencia del republicanismo y supuso para los americanos el objetivo idealista de su revolución. De este objeto fluyó toda la literatura exhortativa americana y todo lo que hizo que su ideología fuera verdaderamente revolucionaria. Esta ideología republicana tanto presumió como ayudó a configurar la concepción americana de la forma en que su sociedad y su política debían ser estructuradas y administradas" (ibidem, pp. 53 y 54, subrayado propio). Sus conclusiones, pues, fueron más allá que las de Bailyn, al menos hasta el momento en que tal ideología vino a fenecer, momento que Wood sitúa cuando fue aprobada la Constitución federal de 1787, pues entonces "la estabilidad del gobierno ya no volvió a descansar, como había ocurrido durante siglos, sobre la personificación de las fuerzas sociales básicas del Estado. En su lugar ahora dependía de evitar que los diversos intereses sociales se incorporaran demasiado firmemente en el gobierno". Así pues, "esta revolución marcó el final de la concepción clásica de la política", ya que "la Constitución representó tanto el climax como el final de la Ilustración Americana, tanto la culminación como el fin de la creencia de que la variedad infinita y la perplejidad de la sociedad podían quedar reducidas a un sistema simple y armonioso". Ibidem, p. 606.

${ }^{21}$ Ibidem, pp. 305 y 306.
} 
Todo este "revisionismo" de corte "republicano" fue conducido a sus últimas consecuencias por J. G. A. Pocock, quien se remontaría aún más atrás para sostener tesis parecidas. Su The Machiavellian Moment. Florentine Political Thought and the Atlantic Republican Tradition (1975) ${ }^{22}$ apuntaba ahora a la existencia de una "tradición clásica" nacida en Europa ${ }^{23}$ y cuyo concepto central sería la "institucionalización de la virtud cívica" que aseguraba la estabilidad temporal de la polis. La mejor forma de conseguirlo y de evitar así su "corrupción" era seguir el modelo de la "república equilibrada" o politeia ${ }^{24}$, que componía a su vez "una estructura en que la disposición de cada ciudadano a anteponer el bien común al suyo propio era condición previa de todo lo demás" 25 , estableciendo un nexo entre personalidad y participación en el poder "en función de las diversidades de la virtud de cada sujeto", y siguiendo, de esta forma, la "teoría del humanismo constitucional" 26 procedente de Aristóteles y su distinción entre los "muchos" y los "pocos"27. De esta forma, el Momento gira en torno a la capacidad del Maquiavelo para gestar una reflexión cuya influencia se prolongaría en el "mundo occidental" durante varios siglos ${ }^{28}$, legando "el concepto de un gobierno equilibrado, de una virtù dinámica, y del papel de las armas y la propiedad en la formación de la personalidad cívica" ${ }^{29}$. Este legado intelectual renacentista alcanzaría más tarde la Oceana inglesa de Harrington $(1656)^{30}$, aunque este autor de la Commonwealth haría descansar la participación en la milicia "sobre la posesión de una propiedad territorial". Pocock entendía en su obra que, tanto los maestros griegos, romanos y renacentistas, como "el canon whig y los autores neoharringtonianos", Milton, Sidney y Bolingbroke, pero también, de nuevo, John Trenchard y Thomas Gordon, habrían establecido una "auctoritas" ${ }^{11}$ que contribuiría poderosa-

\footnotetext{
22 J. G. A. Pocock, The Machiavellian Moment. Florentine Political Thought and the Atlantic Republican Tradition, London, Princeton University Press, 1975; trad. cast. de Marta Vázquez Pimentel y Eloy García, por donde se cita, El momento maquiavélico (con Estudio preliminar de Eloy García), Madrid, Tecnos, 2002.

23 “El empeño de este libro es aislar el 'Momento maquiavélico': es decir, aislar una secuencia en el proceso continuo de la historia del pensamiento" (ibidem, p. 270), siendo "Maquiavelo y Guicciardini", "los actores mayores de ese proceso" (ibidem, p. 267)

${ }^{24}$ Ibidem, p. 268.

${ }^{25}$ Ibidem, pp. 268 y 269.

${ }^{26}$ Ibidem, p. 629.

${ }^{27}$ Distinción que aparece mencionada expresamente en ibidem, p. 153.

${ }^{28}$ Ibidem, pp. 78 y 79.

${ }^{29}$ Ibidem, p. 78. Subrayados propios.

${ }^{30}$ Oceana, así, "representa el momento de un salto adelante paradigmático, de una revisión capital en la historia del pensamiento político inglés y en la propia historia de Inglaterra, a la luz de conceptos extraídos del humanismo cívico y del republicanismo maquiavélico" (ibidem, p. 466).

${ }^{31}$ Ibidem, p. 608.
} 
mente a forjar "los valores norteamericanos" 32 . Así, una de las obras que Pocock rescataba con especial hincapié, y con el fin de demostrar la supervivencia del humanismo cívico en la Historia atlántica, eran aquellas Cato's Letters, representativas para el profesor neozelandés de una toda aquella corriente arrinconada por la historiografía habitual.

A la luz, pues, de toda esta insistencia de los autores citados, creo que merece la pena analizar en qué sentido la obra de Trenchard y Gordon, y cuya influencia en los colonos norteamericanos resulta indudable, respondía realmente a una filosofía política "republicana". Y ello porque podría ayudar asimismo a la comprensión de qué rasgos tuvieron mayor peso en la ideología de los colonos, algo sobre lo que, por otra parte, tanto se ha debatido y se sigue discutiendo entre los historiadores contemporáneos ${ }^{33}$.

\section{Whigs, tories y el gobierno de gabinete: de la Revolución gloriosa al ascenso de los Hannover}

John Trenchard y Thomas Gordon comenzaron a colaborar en enero de 1720 en Londres. La prensa británica de aquellos momentos era un auténtico campo de batalla para las facciones y los grupos políticos, e incluso a menudo quienes eran blanco de sus críticas recurrían a adquirir la cabecera del propio periódico de que se tratara con el fin de acallarlo ${ }^{34}$. Sin embargo, ni siquiera estas maniobras conseguían suprimir las discrepancias. Era tal la pluralidad de opiniones, fuentes de financiación ${ }^{35} \mathrm{e}$ intereses en pugna, que muchos periódicos adoptaron una actitud indócil al gobierno y propensa a criticar abiertamente sus actuaciones ${ }^{36}$. Todo esto en realidad componía un fenómeno cuyo punto de arranque debe encontrarse en la desaparición de la censura previa en 1695, que implicaría también la abolición de las limitaciones geográ-

\footnotetext{
${ }^{32}$ Ibidem, p. 406.

${ }^{33}$ Por citar sólo algunos, además de los ya citados, y sin entrar de lleno en la polémica, vid. J. Appleby, Liberalism and Republicanism in the Historical Imagination, Cambridge, Harvard University Press, 1992; I. Kramnick, "Republican Revisionism Revisited", American Historical Review, vol. 87, $\mathrm{n}^{\circ}$ 3, pp. 629-64; T. L. Pangle, The Spirit of Modern Republicanism. The Moral Vision of the American Founders and the Philosophy of John Locke, Chicago, University of Chicago Press, 1988; P. A. Rahe, Republics Ancient and Modern, 3 vols., Chapel Hill, University of North Carolina Press, 1994; R. E. Shalhope, "Republicanism and Early American Historiography", William \& Mary Quarterly, vol. 39, n 2, 1982;. P. Zuckert, Natural Rights and the New Republicanism, Princeton, Princeton University Press, 1994.

${ }^{34}$ M. Harris, "Print and Politics in the Age of Walpole", en J. Black (ed.), Britain in the Age of Walpole, London, MacMillan, 1984, pp. 189-210, aquí p. 198.

${ }^{35}$ Ibidem, p. 201

${ }^{36}$ H. T. Dickinson, "Popular Politics in the Age of Walpole”, ibidem, pp. 45-68, aquí p. 64.
} 
ficas a su distribución ${ }^{37}$. Al respecto, las corrientes que habían dominado la vida política eran las de los tories y los whigs. La primera también había apoyado la Gloriosa de 1688, si bien con mayor proclividad a las teorías sobre la obediencia al monarca y al gobierno eclesiástico anglicano. La segunda, en cambio, pronto extraería los principales réditos de su firme apoyo a Guillermo de Orange, basado siempre en la idea del consentimiento "popular", traducido en realidad como "parlamentario", y que condicionaba la subida al trono de la dinastía correspondiente. Algo que confirmaría, por cierto, el Act of Settlement de $1701^{38}$. Sin embargo, esto no debería hacernos olvidar una serie de matizaciones que suponen percibir de forma clara que ambos grupos (que no exactamente partidos al modo moderno, pues su nivel organizativo era más bien escaso) se acercaron ya desde esa fecha señalada, con el fin de superar posibles diferencias y admitir un acuerdo político amplio que les permitiera a unos y a otros mantenerse en el Parlamento y evitar posibles purgas, tan habituales en el turbulento pasado inmediatamente anterior ${ }^{39}$. Aunque la literatura al respecto ha solido incluir en las filas tories a los hacendados rurales y en las whigs a los financieros y mercaderes, esta no deja de ser una división aproximada, si bien las ciudades al principio conformaron un bastión perteneciente de manera fundamental a estos últimos ${ }^{40}$.

\footnotetext{
${ }^{37}$ M. Harris, "Print and Politics in the Age of Walpole", ibidem, p. 189.

${ }^{38}$ Esta Ley de Instauración aprobada por el Parlamento vino a excluir a cualquier pretendiente católico al Trono, así como a asegurar la independencia judicial mediante la inamovilidad de los jueces excepto mal comportamiento verificado por las Cámaras. Vid. el texto en J. Esteban (ed.), Constituciones españoles y extranjeras, Madrid, Taurus, 1977.

${ }^{39}$ En 6 de diciembre de 1648 el coronel Pride, bajo la inspiración de Oliver Cromwell, jefe militar del New Model Army, vino a impedir la entrada a la Cámara a un buen número de presbiterianos rivales; al mes siguiente sería decapitado Carlos I Estuardo. El breve período republicano posterior, bajo la égida del líder citado, fue sucedido por la Restauración de Carlos II, que a su vez encarceló y ejecutó a los llamados regicidas, e incluso tras un complot en 1683 (el denominado de Rye House), desató la persecución de disidentes puritanos. Esta represión supuso a su vez el exilio de hombres como Lord Shafestbury y John Locke, que habían mostrado su simpatía como candidato al Trono del Duque de Monmouth. En 1685 estallaría una rebelión de sus partidarios, derrotada por Jacobo II, quien además optaría inmediatamente a continuación por manipular los procesos electorales a las Cámaras de forma que salieran favorecidos sus cercanos. N. Matteucci, Organizzazione del potere e libertà. Storia del constituzionalismo moderno, UTET Librería, Torino, 1988 (hay trad. cast. de Francisco J. Ansuátegui Roig y Manuel Martínez Neira, por donde se cita, Organización del poder y libertad. Historia del constitucionalismo moderno, Trotta, Madrid, 1998, pp. 118 y 143. Toda esta situación de enfrentamiento giraba habitualmente alrededor de tensiones entre aquellos que entendían que alejarse lo más posible del catolicismo era defender mejor la independencia de Inglaterra y las libertades de sus súbditos los partidarios y quienes en cambio eran favorables a reforzar el poder monárquico.

${ }^{40}$ N. Rogers, Whigs and Cities. Popular Politics in the Age of Walpole and Pitt, Oxford, Clarendon Press, p. 5. En Londres, sin embargo, y a partir de 1692, los whigs recortaron el sufragio ciudadano de las elecciones locales, provocando la anómala situación hasta entonces de que los tories
} 
Lo que sí resulta cierto es que unos y otros formaban parte de una élite poderosa, unida a menudo por razones de parentesco y con claro asiento en la propiedad de la tierra, que procuraban incluso quienes prosperaban inicialmente a través de diversos negocios ajenos al entorno rural ${ }^{41}$. La aproximación se produciría hasta el punto de que ambas facciones intentarían encajar los acontecimientos de 1688 de forma que los jacobitas, partidarios del católico Príncipe de Gales, quedaran definitivamente fuera de la competición política. Esta era la base común para poder actuar en medio de una rivalidad que a su vez a menudo se hallaba también atravesada por otras diferencias, principalmente religiosas (entre protestantes más moderados y otros inclinados en cambio al puritanismo), pero también atinente al tipo de intereses económicos en pugna (inmobiliarios, mercantiles, manufactureros o especulativos), y que en el supuesto local guardaba más relación con una lucha de clanes que con otra $\operatorname{cosa}^{42}$.

Con la reina Ana (de 1702 a 1714), los tories fueron los favoritos de la Corona, bajo la hábil conducción del ministro Robert Harley, ministro de 1710 a $1714^{43}$, pero resultarían sustituidos por los whigs con el ascenso de Jorge I de Hannover (17141727), quien era el pariente próximo protestante más cercano a la fenecida monarca, fallecida sin descendencia. El Old Pretender Jacobo, de la casa Estuardo, seguía aspirando también a la Corona y tramaba conspiraciones diversas que le permitieran obtener su objetivo, mediando asimismo la contribución de potencias extranjeras ${ }^{44}$. Así que los whigs, habiendo forjado una alianza con el nuevo rey, extendieron la percepción de que los jacobitas eran una auténtica amenaza para el país e intentaron atribuir a los tories complicidad con sus intenciones, sobre todo a raíz del levantamiento de 1715. Tal pretensión probablemente se alejaba mucho de la realidad, si bien no tenemos demasiados datos sobre complots que, al fin y al cabo, estarían bajo secreto y con pocos rastros de su madeja ${ }^{45}$. Lo que sí resultaba cierto era que el ministerio tory había apoyado el Tratado de Paz de Utrecht de 1713, que dejaba en manos de las potencias católicas a aliados protestantes como la propia casa de Hannover ${ }^{46}$. Un hecho que sin duda ya de entrada no les granjeaba las simpatías de Jorge I, que era al fin y al cabo un príncipe luterano alemán. Por tanto, y nada más llegar al poder éste, se produjo un ahondamiento en la división religiosa que tendría uno de sus principales episodios en

sostuvieran su extensión ante el electorado (ibidem, pp. 20 y 21). Sin duda, este hecho debió influir en la postura de Trenchard y Gordon que viene descrita un poco más adelante.

${ }^{41}$ D. Marshall, Eighteenth Century England, London, Longman, 2a ed, 1974 (1a , de 1962), p. 29.

${ }^{42}$ Ibidem, p. 63.

${ }^{43}$ J. Black, Robert Walpole and the Nature of Politics in Early Eighteenth-Century Britain, St. Martin's Press, New York, 1990, p. 12.

${ }^{44}$ Eighteenth Century England, op. cit., p. 83.

${ }^{45}$ J. Black, "Introduction: an Age of Political Stability?", en Britain in the Age of Walpole, op . cit., pp. 1-22, aquí pp. 4 y 5.

${ }^{46}$ Ibidem, p. 6. 
la controversia bangoriana ${ }^{47}$. Pero es que además los whigs ahora hegemónicos parecieron olvidar muy rápidamente algunos de sus viejos principios. Así, optaron por eliminar las convocatorias electorales cada tres años implantadas en $1694^{48}$, sustituyéndolas por otras septianuales mediante una ley que obtendría asentimiento real en mayo de $1716^{49}$. Tal actuación parecía contradecir su habitual defensa del consentimiento periódicamente renovable en el que basaban la elección de los Comunes. A todo este problema deben añadírsele los propios conflictos existentes entre los más prominentes whigs, que hacían surgir rivalidades entre ellos de cierta gravedad ${ }^{50}$, aunque en 1722 Robert Walpole lograría quedarse solo en esa competición ${ }^{51}$.

En realidad lo que estaba ocurriendo, de manera ya muy clara con lo inmediatos antecesores de este último, es que la porción de la élite que accedía a los ministerios estaba conformando un nuevo modelo político en Gran Bretaña conocido como "gobierno de gabinete", acorde con el robustecimiento gubernamental cuyos inicios databan del ascenso tory durante el reinado de Ana. Sus intenciones eran parecidas y consistentes en domeñar el funcionamiento político de Gran Bretaña de modo que existiera un mando central que disciplinara a aquella oligarquía un tanto díscola ${ }^{52}$. Por ello cobraría especial importancia la fidelización al consejo de ministros de parlamentarios y otros hombres públicos mediante el otorgamiento de pensiones, la venta de cargos y los incentivos a la especulación financiera ${ }^{53}$, al tiempo que se insistía en el refuerzo del fisco ${ }^{54}$ y de la deuda nacional, así como en el impulso de una política mercantilista que protegiera los intereses de Gran Bretaña de manera enérgica y allí donde fuese necesario. La fundación del Banco de Inglaterra en 1694 había sido significativa en este sentido y quizás sea éste el momento al que podemos remontarnos para señalar el cambio de rumbo respecto a composiciones de poder anteriores en las Islas. En esta misma dirección se orientaría en mayo de 1711 la creación de la monopolística Compañía de los Mares del Sur, suministradora de un flujo especulativo

\footnotetext{
${ }^{47}$ Originada por Benjamin Hoadly, obispo de Bangor, y quien la iniciaría en 1717 con afirmaciones que criticaban la autoridad eclesiástica y a sus supuestas atribuciones sobre la conciencia personal.

${ }^{48}$ N. Rogers, Whigs and Cities. Popular Politics in the Age of Walpole and Pitt, Oxford, Clarendon Press, p. 19.

${ }^{49}$ Eighteenth Century England, op. cit., p. 87.

${ }^{50}$ Ibidem, pp. 98-100; y J. Black, "Introduction: an Age of Political Stability?", en Britain in the Age of Walpole, op. cit., pp. 6 y 7.

${ }^{51}$ Ibidem, pp. 7 y 8.

${ }^{52}$ Ibidem, p. 10.

${ }^{53}$ E. Cruickshanks, "The political management of Sir Robert Walpole, 1720-42”, en Britain in the Age of Walpole, op. cit., pp. 23-44, aquí pp. 25 y 26.

${ }^{54}$ Eighteenth Century England, op. cit., p. 154; M. Jubb, "Economic Policy and Economic Development”, en Britain in the Age of Walpole, op. cit., pp. 121-144, aquí pp. 132-137.
} 
en 1720, cuando sus gerentes propusieron asumir toda la deuda nacional, oferta que fue aceptada por el gobierno, en gran parte merced al soborno de diversos políticos y ministros ${ }^{55}$. La burbuja acabó por estallar en pocos meses, originando así la ruina de numerosos inversores ${ }^{56}$, y este es el detonante que pondría en marcha la publicación de las Cartas de Catón.

\section{El contenido de las Cartas}

Obviando toda esta dinámica partidista de la oligarquía inglesa y el hecho de que a pesar de todas sus fluctuaciones confluiría en una misma política gubernamental, latitudinaria y mercantilista, J. A. G. Pocock señala que las Cartas desarrollaban "una crítica de la corrupción en clave inequívocamente maquiavélica y neoharringtoniana, al tiempo que efectuaba una exposición de los supuestos constitutivos de la forma republicana de la que era su opuesto" ${ }^{57}$. Esta perspectiva sería la del propietario de tierras (landowner) endeudado, y comprendería una actitud contraria a los ejércitos permanentes $^{58}$ y a la especulación financiera asociada a la corrupción ${ }^{59}$. El historiador emparenta a continuación este pensamiento con el de Bolingbroke y su círculo ${ }^{60}$, estimando que "su lenguaje era humanista, su enemigo, la modernidad", y encomiando a Walpole en cambio como "el primer estadista moderno".

Pero debe considerarse cuál era la auténtica audiencia de Trenchard y Gordon. Todo ese gubernamentalismo al que se ha aludido tenía sus víctimas, y las últimas de ellas habían sido las de la Burbuja mencionada, pero en realidad la Crisis estricta sólo ocuparía las diez primeras Cato's Letters. Sus autores pretendían, mediante aquel episodio coyuntural, dirigirse a un público descontento con la situación general y pendiente entonces de agruparse bajo alguna propuesta que sobrepasara la habitual línea divisoria entre tories y whigs $s^{61}$, bajo la guía de lo que ellos llamaban "la doctrina de la libertad", es decir, la de que "todo individuo tiene un derecho a vigilar los pasos de aquellos que puedan traicionar su país", porque aunque "el Rey no puede come-

\footnotetext{
${ }^{55}$ M. P. McMahon, The radical whigs, John Trenchard and Thomas Gordon. Libertarian loyalist to the New House of Hannover, University Press of America, Lanham, 1990, pp. 93 y 94.

${ }^{56}$ R. Hamowy, "Introduction”, en T. Gordon, y J. Trenchard, Cato's Letters, or Essays on Liberty, Civil and Religious, and Other Important Subjects, 2 vols., Liberty Fund, Indianapolis, 1995, pp. xxvii-xxx. ${ }^{57}$ El momento maquiavélico, op. cit., p. 570; subrayado propio.

${ }^{58}$ Ibidem, p. 566.

${ }^{59}$ Ibidem, pp. 578 y 580.

${ }^{60}$ Ibidem, p. 581.

${ }^{61}$ Algo que puede advertirse con claridad en Cartas como la n ${ }^{\circ}$ 96: "un tory bajo opresión, o sin posición, es un whig; y un whig con poder para oprimir, es un tory" (Cato's Letters, or Essays on Liberty, op. cit.,p. 687) o la número 16 (ibidem, p. 120; "he visto a menudo a tories honestos defender a whigs bribones por su escaso juicio; y a whigs sin mancha protegiendo a whigs corruptos").
} 
ter crimen [...] los consejeros más altos de los príncipes sí, y de hecho esto ha ocurrido con frecuencia de este modo" 62 . Con el fin de articular un discurso que sirviera para todos esos destinatarios, en efecto, y en esto acierta Pocock, las Cartas acudieron a la retórica del Country, o "patriota", es decir a sus temas recurrentes contra las altas tributaciones, criticando el gasto y la expansión militares y también las maniobras financieras que socavaban el crédito público ${ }^{63}$. Pero esto no significa que hicieran un llamamiento a la abnegación ciudadana que antepusiese el bien común al personal, ni implicaba su adhesión al antiguo "ideal de virtud cívica"64. Más bien utilizaron aquellos temas polémicos para realizar una crítica que finalmente les emparenta con cierta versión radicalizada de Locke aún más comprometida con ciertos derechos, y no con propuestas premodernas más o menos desmesuradas.

Así, para Catón no podía permanecer en pie la tradicional ligazón republicana entre virtud y estatus de freeholder. La "independencia” (su periódico se llamó el Independent Whig), algo tanto moral como material, resultaba ahora relacionada con cierta actividad, no con una posición: "no existe nada moral en la sangre, el título o la posición: sólo las acciones, y los motivos que las producen, resultan ser morales" (Carta 45, "De la igualdad y desigualdad de los hombres") ${ }^{65}$. Para ello debe partirse de la existencia de un agente moral libre y que disfruta de ciertos derechos ("todo hombre es el único señor y árbitro de sus acciones particulares y su propiedad", Carta $62^{66}$ ). El punto de partida de las Cartas, pues, y pese a la lectura pocockiana, era en realidad ese individuo dotado de ciertas facultades inalienables (bitrhrights ${ }^{67}$ ). Catón entiende la propiedad en un sentido incluso más amplio si cabe que el autor del $\mathrm{Se}$ gundo Tratado del Gobierno Civil, puesto que abarcaba, además de la vida (como "seguridad personal", Carta $38^{68}$ ) y los bienes materiales resultantes del propio esfuerzo ("los frutos de la honesta labor de un hombre son la recompensa justa que ésta otorga, establecida por la equidad natural y eterna, siendo su título el usar de aquéllos de la forma que le parezca adecuada", Carta 62 ${ }^{69}$ ), también la libertad de conciencia ("toda religión de un hombre es algo de su posesión", Carta 6070) y de

\footnotetext{
${ }^{62}$ Ibidem, p. 103 (Carta 13).

${ }^{63}$ Ibidem. p. 499: en esta Carta número 69 es en donde mejor se aprecia este componente.

${ }^{64}$ El momento maquiavélico, op. cit., p. 574.

${ }^{65}$ Cato's Letters, op. cit., p. 309.

${ }^{66}$ Ibidem, p. 427.

${ }^{67}$ Ibidem, p. 506 (Carta 70).

${ }^{68}$ Ibidem, p 269.

${ }^{69}$ Ibidem, p 427.

${ }^{70}$ Ibidem, p 414. Comprende la defensa de los ateos, incluso: “"pienso que realmente no existen tales, pero si existiesen, no puedo creer que la verdad y la sobriedad en un ateo sean peores que en otra persona [...] un penique dado por un ateo a un mendigo es mejor limosna que medio penique dado por un creyente; y el buen sentido de un ateo es preferible a los errores de un buen cristiano" (Carta
} 
expresión ("el aseguramiento de la propiedad, y la libertad de expresión, siempre van juntas", Carta $15^{71}$ ), e incluso la libertad de mercado frente a los monopolios (Carta $91^{72}$ ). Esto era lo que componía para ellos la "libertad pública" (algo señalado por el propio título de la Carta 15, referente a la libertad de expresión ${ }^{73}$ ) o el "bien público" (Carta $3^{74}$ ) o simplemente "lo público" (Carta 17) ${ }^{75}$. Trenchard y Gordon sostenían asimismo, y de manera muy similar a Locke, que "en el estado de naturaleza cualquiera tenía derecho repeler las agresiones, y a vengarlas" (Carta 11) ${ }^{76}$. Para evitar la inseguridad derivada de esta situación se había hecho necesario un pacto (Carta 33) ${ }^{77}$, venciendo la inclinación del ser humano a "interferir y combatir a los demás" (idem). Se trataría del "contrato entre un grupo de hombres, acordado sobre ciertas bases de unión y sociedad", de modo que perdían así "parte" de su libertad en aras precisamente de su mejor protección ${ }^{78}$.

Pero, y este es el acento que hace vocacionalmente libertarios a Trenchard y Gordon, los publicistas sostienen que "frecuentemente el remedio demostró ser peor que la enfermedad; y la sociedad humana a menudo no tenía enemigos más grandes que sus propios magistrados, quienes, allá donde se les confiara demasiado poder, siempre tendían a abusar de él" (Carta 33) ${ }^{79}$. Tal posibilidad devuelve a la sociedad a "un estado de guerra" (Carta 25) ${ }^{80}$, puesto que esto es y no otra cosa el que engendra automáticamente la tiranía, régimen que resulta incapaz de garantizar la seguridad ${ }^{81}$. El gobierno es para Trenchard y Gordon un mal menor y hay que vigilarlo mediante una representación erigida como barrera contra su tendencia a invadir el ámbito de los derechos ${ }^{82}$.

49, p. 328). Recordemos que Locke era mucho menos respetuoso: "no deben ser de ninguna forma tolerados quienes niegan la existencia de Dios. Las promesas, convenios y juramentos, que son los lazos de la sociedad humana, no pueden tener poder sobre un ateo. Prescindir de Dios, aunque sea en el pensamiento, lo disuelve todo. Además, aquellos que por su ateísmo socavan y destruyen toda religión, no pueden tener pretensiones de que la religión les otorgue privilegio de tolerancia”. J. Locke, A Letter concerning Toleration [1689-1690]; trad. cast., por donde se cita, a cargo de Pedro Bravo Gala, Carta sobre la Tolerancia, reimp. (1 ${ }^{\mathrm{a}}$ ed., de 1985), Madrid, Tecnos, 1988, p. 57.

${ }^{71}$ Cato's Letters, op. cit., p. 110.

${ }^{72}$ Ibidem, p. 653.

${ }^{73}$ Ibidem, p. 110.

${ }^{74}$ Ibidem, p. 44.

${ }^{75}$ Ibidem, p. 127.

${ }^{76}$ Ibidem, p. 87.

${ }^{77}$ Ibidem, p. 236.

${ }^{78}$ Ibidem.

${ }^{79}$ Cato's Letters, p. 236.

${ }^{80}$ Ibidem, p. 180.

${ }^{81}$ Algo contrario a la ortodoxia hobbesianas que sin embargo atrae en nuestra opinión exageradamente la atención de Pocock, por ejemplo, en la página 578 de su obra mencionada.

82 "No advierto otros medios en la política humana a fin de preservar la libertad pública [...] salvo el de convocar frecuentes elecciones de los comisionados del pueblo". Carta 61, ibidem, p. 422. 
Los gobernantes pueden tornar la situación del súbdito a una peor que aquella en la que los hombres se encontraban sin ellos. De alguna forma, cuando el gobierno aún no se ha instaurado existe una potencia para el desarrollo humano, pero cuando ya se impone de manera tiránica, queda frenada definitivamente cualquier posibilidad de prosperidad. Esta idea de progreso se encuentra en varias Cartas de Trenchard y Gordon, precisamente, como cuando habla de la "mejora del conocimiento" que supuso la Roma republicana (Carta 71) ${ }^{83}$. Y guarda relación con sociedades de mayor movilidad y un número importante de avances tecnológicos y científicos. Por lo demás, también va ligada al comercio: la Carta 64 sostiene que éste "convierte los desiertos en campos fértiles, las aldeas en grandes ciudades, las cabañas en palacios, los mendigos en príncipes" ${ }^{44}$. Es resultado de la "libertad civil", como señala el propio título de esa Carta ${ }^{85}$.

Esta perspectiva, a su vez, corre paralela con toda una visión antropológica referente a las inclinaciones humanas: "el mundo está gobernado por hombres, y ellos por las pasiones, las cuales, encontrándose sin límites y siendo insaciables, resultan terribles siempre que no son controladas" (Carta 33) ${ }^{86}$. Los apetitos del hombre son infinitos (Carta $31^{87}$ ). Algo se mantiene constante, y es el propio deseo humano. Si se siguen ciertas reglas que lo encaucen, resulta posible un resultado positivo, tal y como afirma la Carta 43 ("la ambición de excelencia en cada condición social y por medios honestos, no es sólo legítima, sino laudable, y produce una gran bien a la sociedad" $" 88$ ). De lo contrario, se retrocedería hacia la anarquía o la tiranía. Y el trabajo aparece como integrador de la sociedad ${ }^{89}$, resultando ser fuente de su bienestar y riqueza ("toda felicidad civil y prosperidad es inseparable de la libertad" ${ }^{\circ}$, puesto que "las grandes ciudades que pierden su libertad se convierten en desiertos, y las pequeñas localidades, a causa de ella, se hicieron grandes"91). Así que afianzar su natural desenvolvimiento es el único objeto legítimo del gobierno político ("poseer, en seguridad, los efectos de nuestra industria, es la incitación más poderosa y razona-

\footnotetext{
${ }^{83}$ Ibidem, pp. 517 y 523.

${ }^{84}$ Carta 64, ibidem, p. 443.

${ }^{85} \mathrm{Su}$ texto completo reza: "El comercio y la fuerza naval son consecuencia de la libertad civil, y no pueden subsistir sin ella".

${ }^{86}$ Cato's Letters, op. cit., p. 238.

${ }^{87}$ Ibidem, p. 221, "restless".

${ }^{88}$ Ibidem, p. 295.

${ }^{89}$ Como señala la Carta 62 (p. 427): "por libertad entiendo el poder que tiene cada hombres sobre sus propias acciones, y su derecho a disfrutar de su trabajo, arte e industria, en la medida en que no perjudique a la sociedad o a alguno de sus miembros, quitándoles algo u impidiéndoles disfrutar de algo como lo que él mismo goza". La función integradora en el nuevo modelo de relaciones sociales de la época (J. O. Appleby, "Republicanism and Ideology", American Quarterly, vol. 37, n 4, 1985, p. 470).

${ }^{90}$ Carta 62, Cato's Letters, op. cit., p. 433.

${ }^{91}$ Carta 62, ibidem, p. 432.
} 
ble para ser laborioso", Carta $62^{92}$ ). Hasta el punto de que "si en imponer exacciones sobre el trabajo y las manufacturas excedemos cierta proporción, desanimaremos la industria y destruiremos aquella labor y estos productos. Lo mismo puede afirmarse del comercio y la navegación". Y "tampoco puede ser extorsionado el caballero y freeholder de modo que no pueda ahorrar para el sustento de su familia de forma acorde con su condición original"93.

Esta dignificación de la labor productiva ("la propiedad del pobre será tan sagrada como los privilegios del príncipe, y la ley será el baluarte de ambos"94) tiene su prolongación en una reflexión política sobre el tradicional equilibrio de poderes de la "monarquía mixta", porque tal es precisamente el esquema en el que se ancla el orden legal justo: "un hombre que comete vilezas, no es noble; ni grande, si realiza cosas de escasa entidad: un sobrio campesino es mejor persona que un señor perverso; y un artesano honesto, mejor que un cortesano bellaco" 95 . Lo que se encuentra en consonancia con el hecho de que

"el pueblo, cuando no es mal dirigido o corrompido, generalmente realiza un adecuado juicio sobre las cosas. Tiene cualidades iguales a las de sus superiores [...] no existen tales enormes talentos que resulten exigibles para el gobierno, como pretenden hacernos creer quienes ni siquiera los poseen: los sentimientos honestos y las cualidades comunes, son suficientes; y la administración ha sido siempre mejor ejecutada, así como la libertad pública mejor preservada, alrededor del origen y nacimiento de los estados, cuando la llana honestidad y el sentido común gobernaron solos los asuntos públicos, y la moral de los hombres no fue corrompida por las riquezas y el lujo, ni su comprensión viciada por títulos y distinciones".

Aquí parece haber un rastro claro de cierta lectura de Maquiavelo:

"El pueblo no tiene inclinación a ser bellaco; su fin más alto es la seguridad de sus personas y propiedades. Ninguna ambición le impele; no puede obtener la condición de gran señor, ni poseer importantes títulos, así que no desea ninguno. Ninguna pasión ambiciosa o asocial le inspira; no tiene rivales para ocupar un puesto, ni competidores para apartar; no tiene favorito, alcahuete o relación que mantener: no dispone de oportunidad para el disimulo o la intriga; no sirve al fin de facción alguna; no tiene otro interés que no sea el general" (Carta 24) ${ }^{96}$.

\footnotetext{
${ }^{92}$ Ibidem. "El amor por la libertad es un apetito tan fuertemente enraizado en la naturaleza de las criaturas vivas, que aún el deseo de la propia conservación, que es tenido como el más poderoso, parece encontrarse contenido en él" (Carta 62, ibidem, p. 429).

${ }^{93}$ Carta 10, Cato's Letters, op. cit., pp. 75 y 76.

${ }^{94}$ Carta 63, ibidem, p. 436.

${ }^{95}$ Carta 45, ibidem, p. 309.

${ }^{96}$ Ibidem, p. 174; compárese con los Discursos de Maquiavelo, cuando se refieren al pueblo y por-
} 
Pero esa virtud no es ya sólo, como en el florentino, colectiva, funcional a la república, de "segundo grado" respecto a su "fundador" la independencia individual basada en la igual consideración básica de todos los seres humanos ("los hombres son iguales por naturaleza" ${ }^{8}$ ), y que deriva de la realización de un trabajo productivo y del que uno es su propio dueño ${ }^{99}$. Tal es el sentido de otro párrafo de las Cartas, y que tanto nos recuerda al "tercer estado" de Sièyes: "en vosotros, caballeros, residen los primeros principios del bienestar y el poder. De vuestra labor e industria emana todo lo que se puede llamar riqueza, y que debe ser defendido con vuestras manos; el Rey, la nobleza, los gentilhombres, el clero, los dedicados a las leyes y los oficiales del ejército, todos disfrutan de su grandeza gracias a vuestro sudor y riesgo" (Carta 69) ${ }^{100}$.

La valoración de los muchos parece haber variado con respecto a Maquiavelo drásticamente: ya no configuran un elemento más de la vieja constitución que contempla la sociedad como un todo orgánico con diferentes grupos que realizan funciones más o menos permanentes. Ahora son el agente principal (que no único) de su mantenimiento. Otra cosa es que Trenchard y Gordon vayan más allá hasta adoptar una perspectiva democrática. Probablemente el peso de la tradición y de la Historia inglesas en aquellos autores les compelían a ser fieles a una dinastía ("preservar en el trono a nuestro más excelente soberano, el Rey Jorge", Carta $69^{101}$ ) que al fin y al cabo percibían como garante de la libertad religiosa y de expresión frente a las pretensiones dogmáticas del alto clero y la amenaza exterior de potencias católicas ("preservar la iglesia nacional contra sus entusiastas amigos y sus enemigos", Carta 69102)

qué quiere la libertad: "una pequeña parte quiere ser libre para mandar, pero todos los demás, que son infinitos, desean la libertad para vivir seguros. Porque en todas las repúblicas, de cualquier modo que estén organizadas, sólo cuarenta o cincuenta ciudadanos ocupan los puestos de mando, y el príncipe puede estar seguro respecto de estos pocos, o apartándoles, o dándoles honores en cantidad suficiente para que se sientan contentos, según su condición. Y los otros, a los que les basta con vivir seguros, se satisfacen con facilidad haciendo leyes y ordenamientos en los que, a la vez que se afirma el poder, se garantice la seguridad de todos. Y si un príncipe hace esto y el pueblo ve que no rompe la ley por ninguna circunstancia, comenzará pronto a vivir seguro y contento". N. Maquiavelo, Discorsi sopra la prima deca di Tito Livio (1513-17); trad. cast. de Ana María Martínez Tarancón, por donde se cita, Discursos sobre la Primera Década de Tito Livio, Alianza, Madrid. 1987, p. 80.

${ }^{97}$ R. Del Águila, "Maquiavelo y la teoría política renancentista”, en F. Vallespín (ed.), Historia de la Teoría Política, vol. 2, Madrid, Alianza, 1990, p. 109.

${ }^{98}$ Carta 59, Cato's Letters, op. cit., p. 406.

${ }^{99}$ Por tanto, divergente del criterio de Pocock, vid. El momento..., op. cit., p. 575.

${ }^{100}$ Cato's Letters, op. cit., p. 500.

${ }^{101}$ Ibidem, p. 501. Algo que confirma el título de la Carta 85.

${ }^{102}$ Ibidem. 
y a la que podían dirigirse mediante el derecho de petición (Carta 38 ${ }^{103}$. Pero eso en tal punto de la Historia parece tener más relación con la configuración nacional de aquel país que con el republicanismo clásico. Para Trenchard y Gordon, este modelo ("la constitución de una monarquía limitada", Carta $61^{104}$ ), que incluía el consentimiento a obligarse mediante los representantes, era justificable sólo en la medida en que sirviera para proteger una serie de derechos, pues la mayoría podía equivocarse: "es una noción errónea sobre el gobierno, el que sólo el interés de la mayoría sea consultado, pues cualquier hombre tiene derecho al auxilio de otro para el disfrute y defensa de su propiedad particular; de otra forma, los más podrían vender a los menos y dividir sus propiedades [estates] entre ellos" (Carta 62) ${ }^{105}$.

\section{El supuesto "Republicanismo" de Trenchard y Gordon: los temas recurrentes}

Pero para ser más precisos, y una vez sintetizado el espíritu que domina las Cartas, conviene echar un vistazo a los principales temas del Country, y examinar cómo Trenchard y Gordon los readaptan a una realidad social y económica diferente a la del momento en que nacieron:

1) La crítica a los ejércitos permanentes. La polémica sobre los ejércitos permanentes, aunque previa al ascenso de los Orange, se mantuvo viva gracias a la Standing Army Controversy, provocada por la intención de Guillermo III en 1697 de conservar algunas tropas mercenarias tras la conclusión del tratado de paz de Ryswick $^{106}$. Uno de los escritos dirigidos contra esta política fue In an Argument Shewing That a Standing Army Is Inconsistent with a Free Government, escrito por Walter Moyle (1672-1721) y John Trenchard precisamente ${ }^{107}$. Esta crítica en realidad venía de la mano de una oposición ya tradicional entre los freeholders ingleses, y que databa de sus protestas contra los Estuardo. Pero su sentido en las Cartas de Catón, reflejado en la número 65 principalmente, resulta ya muy distinta. Si bien para buena parte de esa coalición que los publicistas intentaban reunir, sobre todo para los hacendados rurales, la vieja interpretación podía guardar cierta vigencia, para nuestros

${ }^{103}$ Cato's Letters, op. cit., p. 272.

${ }^{104}$ Ibidem, p. 423.

${ }^{105}$ Ibidem, p. 427.

${ }^{106}$ Vid. C. Robbins, The Eighteenth-Century Commonwealthman. Studies in the Transmission, Development, and Circumstance of English Liberal Thought from the Restoration of Charles II until the War with the Thirteen Colonies, reimp. (ed. original de Harvard University Press, Cambridge, 1959), Indianapolis, Liberty Fund, 2004, p. 99.

${ }^{107}$ D. Wootton, "Liberty, Metaphor and Mechanism: "Checks and Balances" and the Origins of Modern Constitutionalism", en D. Womersley (ed.), Liberty and American Experience in the Eighteenth Century, Indianapolis, Liberty Fund, 2006, p. 217 
dos autores, que pretendían hacerse eco también de los artesanos, mercaderes y hombres de oficio de las ciudades (vid. la Carta 69: "a los propietarios, ciudadanos, y burgueses de los condados, ciudades y poblaciones de Gran Bretaña"108), su significado era el de no perjudicar la evolución de sus negocios, transacciones y medios de vida. Es decir, el de no trastornar el discurrir de una labor que creaba prosperidad y riqueza. Lo contrario anulaba incentivos y estímulos a la industria y el comercio y suprimía así la independencia de todos aquéllos. El rechazo a los ejércitos permanentes concordaba con la negativa a satisfacer unas arcas estatales cuya partida mayor sufragaba los pertrechos militares y navales de la Corona, siendo refractaria así también a sus aventuras exteriores (Cartas $86^{109}$ y $17^{110}$ ).

2) La crítica a la especulación. A pesar de sus disgresiones sobre la Burbuja de los Mares del Sur, Trenchard y Gordon no estaban contra la inversión de capital:

\begin{abstract}
"resulta necesario interrogarse sobre lo que se entiende por crédito público de la nación. Primero, puede afirmarse que tal crédito es alto cuando los bienes de una nación encuentran colocación inmediata y resultan vendidos a buen precio; y cuando los comerciantes pueden confiar en ellos, sobre la seguridad de que van a ser reembolsados. Segundo, cuando las tierras y las casas encuentran fácilmente adquirentes; y cuando el dinero va a prestarse a bajo interés, con el fin de sostener el mercado y las manufacturas, y a tales tasas que nos facilita vender más barato que los países vecinos. Tercero, cuando las personas creen que es seguro y ventajoso aventurar mucha mercancía en el tráfico y los negocios, y no guardar el dinero bajo la pechera o enterrarlo. Y cuarto, cuando papel moneda, hipotecas y seguridad particular y pública suponen dinero o lo procuran fácilmente" $(\text { Carta } 4)^{111}$.
\end{abstract}

Todo esto, en consecuencia, orienta decididamente a Trenchard y Gordon hacia la economía de mercado, bien que fuese rudimentaria para nuestros cánones actuales. Eso sí, con el matiz de que las Cartas critican de forma implacable la acción especulativa que socava el crédito público, situándose a favor de los perjudicados por ella. De lo que estaban en contra era de la confusión entre ámbito financiero e instituciones públicas y, sobre todo, de que desastres como los ocurridos produjeran una inseguridad en el tráfico que arruinara a numerosos súbditos británicos, tal y como había sucedido con la Burbuja. Era necesario evitar aquel peligro que tanto perjudi-

\footnotetext{
${ }^{108}$ Cato's Letters, op. cit., p. 497: "to the freeholders, citizens, and burghers of the counties, cities, and towns of Great Britain".

${ }^{109} \mathrm{Su}$ título es el de "las terribles consecuencias de una guerra para Inglaterra, y las razones en contra de comprometerse en ella", ibidem, p. 619.

${ }^{110}$ Ibidem, p. 125, refiriéndose a los ministros que sirven "sus intereses mediante tales guerras".

${ }^{111}$ Ibidem, p. 48.
} 
caba las transacciones comerciales. La deuda pública no podía hincharse excesivamente, porque de lo contrario sólo saldrían beneficiados unos pocos a expensas de la prosperidad pública, es decir, del conjunto de la sociedad, y más concretamente, aniquilaría sus principales recursos y su cohesión: "este es un método que, en lugar de preservar el crédito público, destruye toda la propiedad; sitúa los bienes y riquezas de la nación fuera de sus canales adecuados; y, en lugar de favorecer al cuerpo político, produce sólo úlceras, erupciones, y frecuentemente infecciones epidémicas: causa el hambre del pobre, destruye las manufacturas, arruina nuestra navegación y levanta insurrecciones" (Carta 48) ${ }^{112}$. Esto forma parte de cierto igualitarismo de las Cartas: la corrupción genera mayores desigualdades.

En este último punto hay algo que sí pertenece al pasado y que se conservará luego al otro lado del Atlántico: el miedo a que la facción diera al traste con el adecuado funcionamiento de la coordinación social, un temor de origen netamente republicano. Tal era la base para que Trenchard y Gordon quisieran contribuir al surgimiento de un grupo patriota que no pretendería ser un partido propiamente dicho: "nuestro país abunda en hombres de coraje y entendimiento" (Carta 69) ${ }^{113}$, y debe "olvidarse por tanto, caballeros", esa "tonta y espuria distinción" entre "whig y tory" (Carta 69 ${ }^{114}$ ). Esto se justificaba con la defensa de la constitución tradicional. Se trataba de volver a convertir a la Cámara de los Comunes en una representación-espejo de los electores ("elegir hombres honestos, hombres libres e independientes, y ellos actuarán honestamente por el interés público, que es el tuyo", Carta $69^{115}$ ), mediando un aumento del número de escaños y/o una reducción de los mandatos electorales ("estos diputados deben ser tan numerosos que no puedan existir medios para corromper a la mayoría, o resultar cambiados tan a menudo que no haya tiempo para conseguirlo", Carta $61^{116}$ ) que acogiera así el mecanismo también republicano de la rotatoriedad, con la consiguiente renovación o no del consentimiento tan típica del whiggismo. La virtud quedaba reducida a un ámbito pequeño, el de la que pudieran aportar aquellos hombres de "coraje" que en todo caso seleccionaría el "pueblo" a través de su "celo político" (Carta $\left.\mathrm{n}^{\mathrm{O}} 33^{117}\right)$. La "pasión" (pues así se retrataba a tal actitud popular en el mismo sitio) se situaba de este modo al servicio de la virtud, mediante los correspondientes resortes institucionales. Algo que ya estaba muy cerca del Federalista.

\footnotetext{
112 Ibidem, p. 49.

${ }^{113}$ Ibidem, p. 498.

${ }^{114}$ Ibidem, p. 501.

115 Ibidem, p. 499.

${ }^{116}$ Ibidem, p. 418.

${ }^{117}$ Ibidem, p. 238.
} 


\section{La influencia en el continente americano}

Pero el que finalmente podamos calificar a Trenchard y Gordon como más próximos al liberalismo que como republicanos no explicaría cuál fue exactamente su influencia política en los colonos norteamericanos, apuntada tempranamente por Rossiter ${ }^{118}$ y luego confirmada por otros muchos autores ${ }^{119}$, y sobre todo, en qué sentido fueron interpretados. Las Cartas se utilizaron en reimpresiones y ediciones para lanzar un mensaje que fuera coherente con cierta visión antropológica que se había ido abriendo paso en la nueva sociedad comercial, ¿pero qué relación guardaban ellas, escritas en un contexto geográfico y temporal determinado, con el existente en otro lugar y momento distintos? O lo que es lo mismo, ¿por qué los norteamericanos utilizaron sus textos?

Lo cierto es que los colonos empezaron seleccionando, y ya de forma muy temprana, allá por 1721, una serie de Cartas específicas. El New England Courant, publicación fundada para oponerse abiertamente al gobernador y a los líderes de la Iglesia Puritana de Boston, sostuvo la libertad de crítica apoyándose en la restrictiva interpretación del concepto de "libelo" que Trenchard y Gordon habían asumido en su Carta número $32^{120}$. La libertad de expresión sería reivindicada muy a menudo en aquella colonia durante las décadas posteriores y ello con la inestimable ayuda de la Carta número 15 , ya mencionada un poco más arriba ${ }^{121}$. Un texto que sostenía a la perfección el espíritu combativo de unos colonos que se emanciparían más tarde ("sin libertad de pensamiento no puede haber cosa tal como la sabiduría; ni tampoco libertad pública sin libertad de expresión" ${ }^{122}$ ) y que sería reimpreso por múltiples periódicos a lo largo del tiempo ${ }^{123}$. Pero es que, también en Massachussetts, el bostoniano Independent Advertiser, fundado en 1747 y enfrentado a la administración imperial, acentuaría

${ }^{118}$ C. Rossiter, Seedtime of the republic: The Origin of the American Tradition of Political Liberty, New York, Harcourt, Brace \& Company, 1953, p. 141. Si bien en justicia la primera quizás fue E. C. Cook, Literary Influences in Colonial Newspapers, 1704-1750, New York, Columbia University Press, p. 81

${ }^{119}$ En primer lugar, por los ya citados "revisionistas" ya citados, pero también por otros que se cobijan bajo estudios estadísticos, como D. Lundbergh y H. F. May, "The Enlightened Reader in America, American Quarterly, vol. 28, n. 2, 1976, pp. 266 y 279, o D. S. Lutz, "The Relative Influence of European Writers on Late Eighteenth-Century American Politcal Thought", American Political Science Review, vol. 78, n 1, 1984, p. 193.

${ }^{120}$ H. E. Barry, A Dress Rehearsal for Revolution, John Trenchard and Thomas Gordon's Works in Eighteenth-Century British America, University Press of America, Lanham, 2007, p. 52. Debe considerarse que en al época estaba prohibido criticar al gobierno aunque las conductas reprobables que le fueran imputadas resultaren ciertas (ibidem).

${ }^{121}$ Ibidem, pp. 53 y 55.

${ }^{122}$ Cato's Letters, op. cit., p. 110.

${ }^{123}$ H. E. Barry, A Dress Rehearsal for Revolution, John Trenchard and Thomas Gordon's Works in Eighteenth-Century British America, Lanham, University Press of America, 2007, p. 33. 
el populismo de las Cartas, vertiendo acusaciones de corrupción sobre los representantes de la Corona con ayuda de las números 4 ("Contra los falsos métodos para restaurar el crédito público"), 21 ("Una Carta de John Ketch [...] aseverando su derecho a enjuiciar a los especuladores desmesurados"), 26 ("De los lamentables efectos de la corrupción"), 35 ("De la lealtad"), 37 ("El carácter de un buen y un mal magistrado"), 38 (vid. supra), 45 (vid. supra) y 67 ("Las artes y las ciencias son únicamente efecto de la libertad civil, y resultan destruidos por la opresión y la tiranía"). Su objeto era deslegitimar medidas que se percibían como arbitrarias, especialmente cuando se traducían en impuestos sobre el consumo como los de 1754. Ante este hecho el número 24 de Catón podía dar cumplida cuenta del fenómeno acaecido, así como proponer una respuesta contra los opresores, que consistía una vez más en acudir al control popular del poder ("De la natural honestidad del pueblo, y sobre sus demandas razonables. Cuán importante es para todo gobierno el consultar sus afectos e interés" ${ }^{124}$ ), como pretendía transmitir la Boston Gazzette and Country Journal de 23 de junio de $1755^{125}$.

En el mismo aspecto insistía el New York Weekly Journal en 1733, impreso en la colonia vecina, al publicar la Carta número 38 y titulada "El derecho y la capacidad del pueblo para juzgar al gobierno", de contenido similar a las números 15 y 131, que también editaría. Ya entonces otros periódicos rivales o sostenidos por quienes eran criticados mantuvieron que John Peter Zenger, el editor del New York Weekly, estaba dando una versión torcida de los dos publicistas británicos ${ }^{126}$. Precisamente pronto sería acusado de libelo, dando origen a un caso judicial que sería uno de los más famosos de la Historia emancipatoria estadounidense ${ }^{127}$. El gobernador Cosby pediría a la Asamblea General de la colonia que emprendiera una acción contra Zenger, pero al negarse aquélla tuvo que acudir al Consejo, que demostró ser más proclive a tal actuación ${ }^{128}$. Sin embargo, el defensor del acusado, Andrew Hamilton, pudo ganarse la confianza de un jurado local que apoyaba sus ideas y consiguió la absolución de Zenger basándose precisamente en el número 38 de las Cartas de Catón ${ }^{129}$. Otro de los ejemplos más llamativos que confirma la línea de interpretación señalada fue la que representa Benjamin Franklin en $\operatorname{los} 1730^{130}$. El futuro signatario de la Declaración no dudaba en recoger extractos escogidos que combinaba también, como en

\footnotetext{
${ }^{124}$ Cato's Letters, op. cit., pp. 174-179.

${ }^{125}$ H. E. Barry, A Dress Rehearsal..., op. cit., pp. 55-58.

${ }^{126}$ Ibidem, p. 66.

${ }^{127}$ R. A. Rutland, "Bill of rights and the first ten amendments to the Constitution", en J. P. Greene y J. R. Pole (eds.), The Blackwell Encyclopedia of the American Revolution, reimp. (de la $1^{\mathrm{a}}$ ed. de 1991), Cambridge, Basil Blackwell, 1994, pp. 271-275, aquí p. 271.

${ }^{128}$ H. E. Barry, A Dress Rehearsal..., op. cit., p. 68.

${ }^{129}$ Ibidem, p. 70. El ensayo número 38 sería uno de los publicados con más frecuencia en las colonias durante toda la etapa previa a la independencia (ibidem, p. 34).

${ }^{130}$ Ibidem, p. 95.
} 
los casos bostoniano y neoyorquino, para sostener la idea de un gobierno bajo fuerte control popular y por tanto, el refuerzo de las asambleas conformadas por los colonos en detrimento de los gobernadores y sus consejeros.

Todos los casos analizados sobre la prensa editada en las colonias, y con mayor intensidad a medida que nos vamos acercando a la fecha de emancipación, apuntan en idéntica dirección. El Massachussetts Spy, el New York Journal o el Pennsylvania Journal demuestran una postura similar. Las Cartas publicadas fueron las ya citadas números 15,18 y 33 , y a veces sin señalar a sus auténticos autores ${ }^{131}$, pues tal era la identificación con sus proclamas. Ésta era mediada por cierto proceso selectivo, pero no hacía falta nada más. Las famosas Letters from a Farmer in Pennsylvania (1768) también aludieron a las Cartas de Catón, e incluso su autor, John Dickinson, no dudó en imitarlas de forma manifiesta en algún caso. El tono perentorio de Trenchard y Gordon décadas atrás aún podía mantener efectos agitadores mucho más tarde. Debido a que sus ensayos "eran sencillos y altamente polémicos, las personas de estatus medio y más bajo podían comprender sus argumentos bastante bien y probablemente los encontraban interesantes de leer"132. Con ellos se consolidaba una "lengua de los derechos" 133 y se reforzaba el papel de las asambleas populares. Desde este punto los colonos pasarían luego a otra fase, en la cual se vería "la aplicación constructiva de esas ideas y la exploración de sus implicaciones, límites y posibilidades en la escritura y reescritura de las primeras constituciones estatales" antes de la federal, y de este modo explorarían "la naturaleza de las constituciones escritas y del poder constituido" y "los problemas de separar los poderes vigentes del gobierno para lograr equilibrios en sociedades de un solo orden", poniendo a prueba "la naturaleza de la representación, el significado eficiente de la soberanía del pueblo y los derechos individuales". Acudirían así a lo que Bailyn denomina, de este modo, como "escritura constitucional" 134 .

Pero Trenchard y Gordon, por lo demás y como ya se ha podido percibir, habían aseverado que la mejor forma de gobierno quizás era una monarquía bien asentada, tal y como expresaba el su Carta número 85 ("Gran Bretaña es incapaz de cualquier otro gobierno que no sea una monarquía limitada"), un texto que precisamente no tendría eco en América ${ }^{135}$. Los dos autores ingleses creían que quienes debían enten-

\footnotetext{
${ }^{131}$ Ibidem, pp. 103-108.

132 Ibidem, p. 90.

${ }^{133}$ R. A. Primus, The American Language of Rights, Cambridge, Cambridge University Press, 1999; y J. P. REID, Constitutional History of the American Revolution; The Authority of Rights, Wisconsisn, University of Wisconsin Press, 1986.

${ }^{134}$ Lo que Bailyn denomina “escritura constitucional”. Los orígenes ideológicos..., op. cit., p. 318.

${ }^{135}$ No está en ninguna de las docientos setenta ediciones periodísticas evaluadas por H. E. Barry, A Dress Rehearsal..., op. cit., pp. 118-132.
} 
der de estos asuntos pertenecían a una categoría mucho más reducida de ciudadanos, y eran menos optimistas con respecto a la capacidad epistémica colectiva del pueblo $^{136}$. De ahí el hincapié que la prensa norteamericana prefirió hacer en sus pasajes sobre la igualdad, como el de la Carta 38 ("todo campesino sabe distinguir un buen gobierno de otro malo, a través de sus efectos: sabe si obtiene los frutos de su labor, y si los disfruta en paz y seguridad"; y el "gobierno no es otra cosa más que un fideicomiso otorgado a unos pocos por todos, o por la mayoría"137). Con ellos, los periódicos americanos interpretaban ésta en un sentido más amplio, soslayando que Trenchard y Gordon habían querido referirse fundamentalmente a una dimensión política y no tanto a otra de carácter social. Esta nueva perspectiva venía de la mano de la inexistencia en el Nuevo Mundo de barreras tan fuertes como en Inglaterra, en medio de un proceso favorecedor y propiciado por una movilidad más intensa, la disponibilidad de mayores extensiones de terreno y una serie de cambios que difuminaban la jerarquía procedente de la vieja Europa ${ }^{138}$. No era ya tiempo de defender algún tipo de constitución política "mixta" 139 , que en realidad se percibía como liquidada entonces el continente americano ${ }^{140}$. De hecho los propios federalistas hicieron un reconocimiento implícito de la soberanía popular, al sostener que la Constitución federal de 1787 habría de "fundarse en el asentimiento y la ratificación del pueblo americano" 141 , en la línea de lo señalado por el frontispicio constitucional ("nosotros, el Pueblo de los Estados Unidos").

En contra de lo que pudiera suponerse siguiendo la lectura de Pocock, la predilección de los colonos estuvo dirigida hacia aquellas Cartas de Trenchard y Gordon que versaban precisamente sobre las libertades de conciencia y de expresión, el derecho de

\footnotetext{
${ }^{136}$ Vid. supra.

${ }^{137}$ Cato's Letters, op. cit., p. 267, subrayado propio.

${ }^{138}$ G, S. Wood, The Radicalism of the American Revolution, New York, Random House, 1993, passim, y con respecto a la inexistencia en América de una Iglesia oficial hegemónica, vid. E. S. Gaustad, "Religion before the Revolution", en J. P. Greene y J. R. Pole (eds.), The Blackwell Encyclopedia of the American Revolution, op. cit., pp. 64-70.

${ }^{139}$ N. Matteucci, Organizzazione del potere e libertà. Storia del constituzionalismo moderno, UTET Librería, Torino, 1988; trad. cast. de Francisco J. Ansuátegui Roig y Manuel Martínez Neira, por donde se cita, Organización del poder y libertad. Historia del constitucionalismo moderno, Madrid, Trotta, 1998, p. 206.

${ }^{140}$ Son significativas, así, las palabras de Paine en su Sentido Común: "la Constitución de Inglaterra es tan desorbitadamente compleja que la nación puede sufrir durante años sin ser capaz de descubrir en qué sitio reside la falta". T. PAINE, Common Sense (1776); trad. cast. de Ramón Soriano y Enrique Bocardo, por donde se cita, "El Sentido Común", en El sentido común y otros escritos (eds., id.), Madrid, Tecnos, 1990, p. 8.

${ }^{141}$ A. Hamilton, J. Jay y J. Madison, The Federalist Papers (1787-1788); trad. cast. de Gustavo R. Velasco, El Federalista, $2^{\circ}$ ed. (1 ${ }^{\mathrm{a}}$, de 1943), México, Fondo de Cultura Económica, 2001, p. 161 (El Federalista $\left.\mathrm{n}^{\circ} 39\right)$.
} 
propiedad frente a los impuestos, o el de representación que veían vulnerado por una supuesta de carácter "virtual" en los Comunes ${ }^{142}$. La prensa americana seleccionaba las Cartas que entendía más apropiadas para distintos conflictos entre grupos, o en relación con la elite de la metrópoli, bajo un criterio que suponía por sí mismo la asunción de supuestos populistas bastante más acentuados que los de Trenchard y Gordon y que preparaban el camino para las corrientes democratizadoras que culminaron con la Constitución de 1787. Uno de los ataques que más gustaba de reproducir era el que ambos autores habían dirigido contra los títulos de lustre y a favor de la retirada popular de la confianza a los cargos públicos. Pero los temas de la burbuja financiera que tanto menciona Pocock no fueron tomados en cuenta por una literatura a la cual no interesaba una coyuntura tan estrecha y animada por circunstancias y partidos que al fin y al cabo eran locales y propiamente británicos, y que se volvían tanto más lejanos cuanto más se alejaba el centro de poder identificado con el Rey y las Cámaras de Westminster.

Todo esto no suprime el hecho, sin embargo, de que los colonos mantuvieran cierta retórica sobre el bien común, incluso muy pronunciada en el caso de algunos autores (Benjamin Rush, por ejemplo ${ }^{143}$ ). Pero su objeto ya era distinto también al de las antiguas comunidades, ya fuera de la Antigüedad, ya del Renacimiento. A caballo entre la separación de un imperio, la emergencia de varios Estados y la inexistencia aún de una nación propiamente dicha, los norteamericanos necesitaban una concepción que implicara unidad, pero que no fuese ninguna de aquellas entidades. La república federal fue la que sustituyó a una Confederación inicial basada en un documento (los "Artículos") insuficiente para enfrentarse a los nuevos retos. La Constitución de 1787 supuso un experimento atrevido, considerando que ninguna república había llegado a ocupar un territorio tan extenso, y sobre todo, con aquel nivel de igualitarismo sumamente extraño en Europa. El "pueblo" sería el sujeto que encarnaría ahora a un cuerpo político ansioso de afianzamiento y articulado sobre una división del poder de origen republicano, con idénticos procedimientos, mecanismos y estructuras. Aparecía una nueva comunidad y con ella otra fórmula de legitimación más extensa y horizontal, pero luego también inexorable en su centralización.

\footnotetext{
${ }^{142}$ Diversos autores, como Soame Jenyns, Thomas Whately, Martin Howard o Samuel Seabury, entendían, expresando así la opinión de la metrópoli, que pese a no poder enviar delegados a Westminster, los colonos se hallaban representados allí, del mismo modo que en Inglaterra ocurría con quienes carecían de propiedad plena o con ciertas localidades. Vid. Objections to the Taxation of our American Colonies by the Legislature of Great Britain, Briefly Considered (1765), en The Works of Soame Jenyns, Vol. II, 2 a ed., London, T. Cadell, 1793, pp. 192-195), así como E. S. Morgan, Inventing the People; The Rise of Popular Sovereign in England and America, New York, W.W. Norton and Co., 1989, p. 240.

${ }^{143}$ D. Herzog, "Some Questions for Republicans", Political Theory, vol. 14, n 3, 1986, pp. 483-486.
} 
Y esta ya es otra historia que Trenchard y Gordon, desde luego, ni siquiera pudieron probablemente haber soñado. La Historia de la democracia moderna o representativa, o lo que Paine calificaría de "gobierno representativo"144. Las Cartas de Catón expresaban la limitación del liberalismo sin democracia: no se sabía con precisión dónde estaba el pueblo ni cómo conformaba su presencia de manera "fuerte", superior a otros poderes (y no sólo en origen, como era típico de la tradición aristotélica). Los revolucionarios norteamericanos, y luego los franceses, ofrecieron una respuesta que, definitivamente, no agradaría en absoluto en Gran Bretaña, excepto a unos poco radicales y que cortaría definitivamente el cordón umbilical del discurso admitido por la elites, las cuales a partir de 1776 probablemente no hubieran sido tan condescendientes con Trenchard y Gordon como parece que lo fue la administración walpoliana ${ }^{145}$, y que de facto persiguieron a quienes pretendieron identificarse como republicanos desde $1791^{146}$. Una escisión territorial al otro lado del Atlántico y el estruendo democrático acompañado de la decapitación de Luis XVI inducían a no permitirse tanta veleidad. Los esfuerzos de los reformadores radicales de las Islas tuvieron que redoblarse en las próximas décadas, frente a un conservadurismo político y social que predominó durante mucho tiempo.

\footnotetext{
${ }^{144}$ T. Paine, Dissertation on first principles of government (1795); trad. cast. de Ramón Soriano y Enrique Bocardo, por donde se cita, en El sentido común y otros escritos (eds., id.), Madrid, Tecnos, 1990, p. 73.

145 Thomas Gordon fue nombrado administrador de licencias vitícolas en 1733. M. P. McMahon, The radical whigs, John Trenchard and Thomas Gordon. Libertarian loyalists to the New House of Hannover, Lanham, University Press of America, 1990, p. 85.

${ }^{146}$ M. Philp, "English Republicanism in the 1790s", Journal of Political Philosophy, vol. 6, nº 3, 1998, passim.
} 